\title{
IMPACTOS DIRETOS E INDIRETOS NO DESMAME PRECOCE
}

\author{
Carolina Mangia Dutra Silva ${ }^{1}$ \\ Denise Mary Costa de Oliveira ${ }^{2}$
}

RESUMO: Esse trabalho tem por objetivo avaliar quais os impactos diretos e indiretos do desmame precoce, principalmente pelo alto índice de interrupção da amamentação. A amamentação é o primeiro contato do recém-nascido com a mãe, e de acordo com a Organização Mundial da Saúde (OMS), é a principal fonte de nutrientes e um dos principais fatores da promoção de saúde, e recomenda-se que seja a alimentação exclusiva até os seis meses de idade, evitando milhares de mortes anualmente por todo o mundo. Segundo dados de especialistas e autores que estudam as áreas da saúde e social, muitos fatores, principalmente os sociais e econômicos, fazem o índice de amamentação diminuir, causando problemas de saúde pública. Porém, podemos ressaltar um outro lado pouco observado e falado que é o desmame precoce pela participação da mulher na sociedade capitalista, juntamente com a falta de conhecimento sobre o benefício do aleitamento. Através dessas informações, juntamente com as consequências a longo prazo, como diminuição da qualidade de vida das famílias, causadas pelo desmame e com as informações fornecidas pelos especialistas da área, podemos conferir os impactos diretos e diretos causados pelo desmame precoce.

Palavras-chave: Desmame. Precoce. Amamentação. Impactos. Aleitamento materno.

ABSTRATC: This work aims to assess the direct and indirect impacts of early weaning, mainly due to the high rate of interruption of breastfeeding. Breastfeeding is the newborn's first contact with the mother, and according to the World Health Organization (WHO), it is the main source of nutrients and one of the main factors in health promotion, and it is recommended that it be the exclusive feeding until six months of age, preventing thousands of deaths annually around the world. According to data from specialists and authors who study the areas of health and social, many factors, especially social and economic, cause the rate of breastfeeding to decrease, causing public health problems. However, we can highlight another side that has been little observed and talked about, which is early weaning

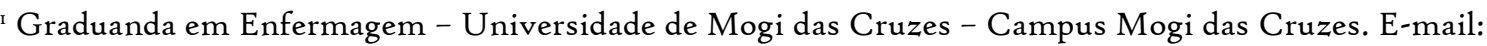
carolina_mangia@hotmail.com.

${ }^{2}$ Mestre em Ciências e Tecnologia em Saúde - Universidade de Mogi das Cruzes - Campus Mogi das Cruzes. E-mail: denisemarycostanurse@gmail.com.
} 
due to the participation of women in capitalist society, together with the lack of knowledge about the benefits of breastfeeding. Through this information, together with the long-term consequences, such as decreased quality of life for families, caused by weaning and with the information provided by specialists in the area, we can see the direct and direct impacts caused by early weaning.

Keywords: Weaning. Precocious. Breast-feeding. Impacts. Breastfeeding.

\section{INTRODUÇÃO}

A amamentação é o primeiro contato do recém-nascido com nutrients fora do útero. Esse primeiro contato com a alimentação é responsável por desenvolver os anticorpos necessários para garantir o início de uma segurança na saúde. Como diria CAMPESTRINE, 1992, essa troca de nutrientees é responsável para assegurar muitas necessidades da criança em desenvolvimento, é compatível com o ambiente da mãe e filho.

A Organização Mundial da Saúde (OMS) garante e recomenda o aleitamento como alimentação exclusiva até os seis meses de idade, e, após, recomenda a introdução de alimentos na rotina da criança.

O desmame precoce é a interrupção do aleitamento materno exclusivo ao peito, antes do lactante haver completado seis meses de vida, independentemente de a decisão ser materna ou não, e do motivo de tal interrupção. (CABRAL; CAMPESTRINI, 20Io).

O aleitamento materno e a alimentação adequada no primeiro ano de vida são os principais fatores determinantes do crescimento e desenvolvimento adequado e da condição de saúde da criança pequena. (BARBOSA et al, 2009).

Tal importância da-se baseada em históricos negativos de crianças que desenvolveram algum certo tipo de não conformidade nutróloga em seu sistema e pelo problema de saúde coletivo que é gerado conforme o desmame fica cada vez mais comum. Um grande exemplo é o aumento da obesidade infantil e alergias nos países desenvolvidos pelo alto índice de aleitamento artificial. Já nos países em desenvolvimento, desencadeou o oposto, como doenças respiratórias, desnutrição e infecções, uma vez que não possuem condições para arcar com aleitamento artificial.

Em ambas situações podemos observar que o problema de saúde pública é gerado independentemente do desenvolvimento do país, pois é a consequência biológica da natureza do problema, uma vez que está ligada diretamente a mortalidade infantil. 
Por essas variáveis precisamos estudar toda a trajetória desde a raiz da problemática para podermos entender as consequências como um todo. Não existem dúvidas de que boa parte da qualidade de vida humana é gerada através do aleitamento materno, porém ainda é preciso defrontar os empecimentos existentes, como a falta de incitação do aleitamento, a não assistência a famílias recém geradas, o mundo capitalista e a agilidade de fazer as coisas, e as doenças e problemas de saúde causadas pelo desmame precoce.

\section{OBJETIVOS}

Identificar as causas de desmame precoce e seus impactos na vida da criança e da progenitora.

\section{MÉTODO}

Trata-se de uma revisão integrativa. Tal revisão é um método que proporciona a síntese de conhecimento e a incorporação da aplicabilidade de resultados de estudos significativos na prática (SOUZA et al 2016).

A busca dos dados do presente estudo será realizada por meio de uma consulta informatizada no banco de dados bibliográficos da Biblioteca Virtual em Saúde (BVS) com artigos indexados nas bases de dados da Literatura Latino-Americana em Ciências de Saúde (LILACS), e Scientific Eletronic Library Online (SCIELO), por apresentarem expressivo acervo na temática desse estudo.

Os descritores utilizados nessa pesquisa serão: VIEIRA, Doralice Barbosa. Desvantagens do desmame precoce e o papel do enfermeiro. Brazilian Journal of Development, v. 6, n. 6, p. 35163-35184, 2020; Sobre Amamentação. TEMA-Revista Eletrônica de Ciências (ISSN 2175-9553), v. I4, n. 20; 21, 2014. validados pelos Descritores de Ciência em Saúde (DECs).

$\mathrm{Na}$ busca de resultados, serão considerados os seguintes critérios de inclusão: Artigos e revistas relacionados a saúde da mulher e do Recém- Nascido.

Serão considerados critérios de exclusão: Publicações anteriores a 2010, artigos na língua estrangeira e, que não contemplam a temática. 
Para a busca de títulos e resumos afins, será selecionado o descritor principal "recémnascido" sendo cruzado com cada um dos demais descritores do estudo.

Após o levantamento da literatura relacionada à temática, será realizada seleções de textos pertinentes com a categorização e interpretação das ações não farmacológicas implementadas pela Enfermagem ao RN com SAN, segundo a análise de conteúdo (BARDIN, 2004).

Para Bardin (2004) inicialmente faz-se uma criteriosa leitura dos artigos para o agrupamento de informações de significados semelhantes, levando à formação de subtemas, elaborados pelo pesquisador, podendo ser organizados em forma de Quadros contendo: nome dos autores, título do estudo, objetivos e respectivos achados, sendo analisados na discussão do estudo.

Esse projeto não necessitará ser submetido ao Comitê de Ética da Universidade de Mogi das Cruzes, por tratar-se de revisão integrativa, segundo os preceitos da Resolução do Conselho Nacional de Saúde 466/ı2.

\section{RESULTADOS E DISCUSSÃO}

Foram encontrados 20 estudos, sendo selecionados is para leitura dos resumos e apenas 9 publicações permanecendo para a discussão. As informações foram processadas e os resultados interpretados a partir da análise das mesmas. A pesquisa foi realizada com publicações no período de 1994 a 2021 conforme citado na metodologia. Os artigos selecionados para a pesquisa foram avaliados através da leitura dos títulos que condiziam com o tema estudado. Em seguida, foram avaliados os resumos que continham informações referentes ao tema abordado, e por fim, a leitura completa dos artigos que apresentam o conteúdo para atender o objetivo proposto.

Os dados foram apresentados em quadros possibilitando uma melhor visualização dos dados levantados na leitura e interpretação científica, seguidos de sua discussão. Segue abaixo o quadro das principais características dos estudos utilizados na pesquisa. 
Quadro I: Caracterização da importância do aleitamento materno

\begin{tabular}{|c|c|c|c|}
\hline AUTORES ANO & MÉTODO & $\begin{array}{c}\text { PALAVRAS } \\
\text { CHAVES }\end{array}$ & ACHADOS \\
\hline $\begin{array}{l}\text { ELSA GIUGLIANI, } \\
1994\end{array}$ & $\begin{array}{l}\text { Pesquisa com } \\
\text { abordagem } \\
\text { qualitativa e } \\
\text { quantitativa }\end{array}$ & $\begin{array}{l}\text { Amamentação } \\
\text { exclusiva; } \\
\text { prevenção; mortes; } \\
\text { crianças. }\end{array}$ & $\begin{array}{l}\text { Importância do aleitamento materno } \\
\text { para a preservação da vida das crianças } \\
\text { e prevenção contra a morte infantil. }\end{array}$ \\
\hline $\begin{array}{l}\text { LÚCIA } \\
\text { MAGALH ̃̃ES, } 2019\end{array}$ & $\begin{array}{l}\text { Pesquisa com } \\
\text { abordagem } \\
\text { qualitativa }\end{array}$ & $\begin{array}{l}\text { Leite; amamento; } \\
\text { criança; saúde; } \\
\text { cultura; mãe; }\end{array}$ & $\begin{array}{l}\text { Informaçóes sobre a cultura do } \\
\text { aleitamento e o quanto o mesmo é } \\
\text { importante para o imunológico de mãe } \\
\text { e filho. }\end{array}$ \\
\hline 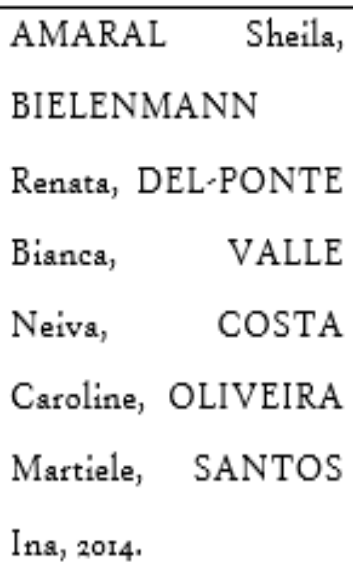 & $\begin{array}{l}\text { Pesquisa com } \\
\text { abordagem } \\
\text { qualitativa e } \\
\text { quantitativa }\end{array}$ & $\begin{array}{l}\text { Prevenção; } \\
\text { mortalidade; } \\
\text { amamentação; } \\
\text { prática; } \\
\text { alimentação; } \\
\text { sucesso. }\end{array}$ & $\begin{array}{l}\text { A escolha pessoal influencia na decisão, } \\
\text { além do reconhecimento do direito } \mathrm{da} \\
\mathrm{mãe} \text { e fatores de sucesso da } \\
\text { amamentação. }\end{array}$ \\
\hline
\end{tabular}

Sabemos que a amamentação tem uma importância constante no nosso mundo. Além do privilégio e laço entre a mãe e o filho.

Entende-se que para qualquer afeto entre os seres humanos devemos incluir confiança e amor, sendo assim, a amamentação faz parte desse vínculo.

Diante de todos os laços causados pelo amamento, a prática é aconselhada desde o primeiro dia de vida, até o sexto mês de vida do bebê, desde que seja natural da mãe, com nenhuma alteração ou mistura, como água ou leite de outro mamífero. 
O leite materno é o alimento adequado para as crianças nos primeiros meses de vida, tanto do ponto de vista nutritivo e imunológico quanto no plano psicológico, além de favorecer o vínculo mãe-filho quando o ato de amamentar é bem vivenciado pelas mães. Contudo, a despeito dessas características, a amamentação é, também, uma relação humana, portanto inscrita na cultura e submetida à esfera social inserindo uma complexidade própria ao fenômeno que transcende o aspecto nutricional que lhe é inerente e ultrapassa a díade mãe-filho. (LÚCIA MAGALHÃES, 2019)

O aleitamento é o meio de proporcionar uma qualidade de vida através da prática da alimentação adequada para a criança nos seus primeiros meses de vida.

O ministério da saúde recomenda o aleitamento materno até os dois anos de vida para proporcionar uma qualidade nutricional para o desenvolvimento da criança.

O leite oferecido pela mãe é composto por inúmeras composições nutricionais, como carboidratos, vitaminas, proteínas e também $88 \%$ de água.

Antepassados sempre indicaram sucos e chás ou até mesmo a água. Mas a composição do leite materno não nos dá a carência dessa ingestão, sendo o principal composto para o crescimento do bebê.

A amamentação auxilia nos pontos dos índices de mortalidade infantil, pois acarreta em uma barreira de proteção para o recém-nascido, ajudando-o no desenvolvimento da estrutura corporal. O contato entre a mãe e o filho é uma necessidade de sentidos, onde a criança se sentirá segura e criará seus contatos e primeiros laços. $O$ aleitamento beneficia a mãe em outros pontos como prevenir uma hemorragia após o parto. Diante dessa observação, algumas mães acabam trazendo para a pauta assuntos e histórias antigas de sua família com relação a amamentação. Sabemos que famílias antigas levavam em consideração inúmeros costumes, como por exemplo: amamentar até sair a última gota de leite. Outro contexto familiar muito famoso é o aspecto estético.

Atribui-se ao aleitamento materno a prevenção de mais de 6 milhões de mortes em crianças menores de 12 meses a cada ano. Se a amamentação ótima (exclusiva até 4-6 meses e parcial até o final do primeiro ano de vida) fosse praticada universalmente, mais 2 milhões de mortes (de um total de 9 milhões) poderiam ser evitadas7. Vários estudos têm mostrado o efeito protetor do leite materno contra a mortalidade infantil, especialmente nos países em desenvolvimento. Habicht et al8, de uma maneira muito elegante, demostraram que a associação entre aleitamento materno e baixo índice de mortalidade no primeiro ano de vida persiste mesmo quando os vícios comuns cometidos em pesquisas deste tipo (controle inadequado de fatores de confusão e a não observância do fenômeno da causalidade reversa - morte ou doença terminal interferindo na amamentação) são levados em consideração. (ELSA GIUGLIANI, 1994). 
Quadro 2: Benefícios do aleitamento materno para a saúde da mãe e aconselhamento profissional

\begin{tabular}{|c|l|l|l|}
\hline AUTORES ANO & MÉTODO & $\begin{array}{c}\text { PALAVRAS } \\
\text { CHAVES }\end{array}$ & \multicolumn{1}{|c|}{ ACHADOS } \\
\hline $\begin{array}{c}\text { ANTUNES et al, } \\
2006\end{array}$ & $\begin{array}{l}\text { Pesquisa } \\
\text { com } \\
\text { abordagem } \\
\text { qualitativa }\end{array}$ & $\begin{array}{l}\text { Leite materno; } \\
\text { benefícios; } \\
\text { mulher. }\end{array}$ & $\begin{array}{l}\text { Benefícios da amamentação } \\
\text { tanto para a criança quanto para } \\
\text { a progenitora. }\end{array}$ \\
\hline $\begin{array}{c}\text { BUENO LGS, } \\
2004\end{array}$ & $\begin{array}{l}\text { Pesquisa } \\
\text { com } \\
\text { abordagem } \\
\text { qualitativa }\end{array}$ & $\begin{array}{l}\text { Apoio; } \\
\text { amamentação; } \\
\text { dificuldades; } \\
\text { especialistas; } \\
\text { assistência. }\end{array}$ & $\begin{array}{l}\text { Importância do aconselhamento } \\
\text { profissional para a mãe no } \\
\text { período pós parto, melhorando a } \\
\text { qualidade de vida e passando } \\
\text { pelo puerpério com assistência. }\end{array}$ \\
\hline $\begin{array}{c}\text { MOUTINHO } \\
\text { Karina, 20Io }\end{array}$ & $\begin{array}{l}\text { Pesquisa } \\
\text { com } \\
\text { abordagem } \\
\text { qualitativa }\end{array}$ & $\begin{array}{l}\text { Investigação; } \\
\text { interminação; } \\
\text { amamentação; } \\
\text { incentivo; } \\
\text { aleitamento } \\
\text { materno. }\end{array}$ & $\begin{array}{l}\text { Necessidade de treinamento da } \\
\text { equipe de saúde para incentivar } \\
\text { para informar as vantagens do } \\
\text { aleitamento }\end{array}$ \\
\hline
\end{tabular}

A amamentação é um período de extrema importância após o parto. Mas é algo que

deve ser orientado desde a primeira semana da descoberta da gravidez. Como todos os cuidados de vitaminas, exames e acolhimento em todo apoio que a mãe precisa, principalmente em relação as ansiedades e transtornos que podem causar com a dor física e mental, assim promovendo segurança e conforto.

Sabe-se que os benefícios da amamentação para saúde da mulher ainda não são muito informados durante as consultas de pré-natal. Todas as informações são voltadas para os benefícios que o leite materno tem para o bebê, embora saibamos que, para a mulher, a amamentação produz ganhos importantes, como o favorecimento do vínculo afetivo, satisfazendo e suprindo a separação abrupta ocorrida no momento do parto (ANTUNES et al, 2006).

O profissional será o responsável para aconselhar e oferecer todo conhecimento sobre o assunto, para deixar a mãe confortável para amamentar, e oferecer os benefícios do leite materno. Auxiliando inclusive em formas de posições para segurar o recém-nascido, para que ela consiga amamentar de uma forma tranquila e segura.

Para alcançar um objetivo claro, o profissional deve ter um atendimento humanizado e individualizado, para deixar a mãe o mais confortável possível com a ideia. Buscando 
entender todos os medos e anseios durante a gestação, afim de que nenhuma crença militante a faça optar pelo desmame. É preciso e acolher as angústias da mãe.

Para a manutenção da amamentação, a mãe precisa receber apoio e ajuda centrada nas dificuldades específicas ou nas suas crises de autoconfiança. No seguimento, a atenção ao acolhimento é semelhante à do acompanhamento pré-natal. A dinâmica de grupo antes das consultas oferece às mães informações relevantes, deixando-as mais tranquilas e facilitando a comunicação com o profissional durante a assistência. (BUENO LGS, 2004).

O apoio e a manutenção da amamentação fazem parte do cotidiano desse período com a mãe. Os históricos familiares influenciam fortemente que a mãe aceite esse período de amamentação, então acabamos descobrindo inúmeros mitos e crenças durante esse período, trazidos por pessoas muito próximas da mãe, como avós, mães, tias e até bisavós, que podem influências positivamente ou negativamente esse processo de escolha da mãe.

Quadro 3: Impactos negativos do desmame precoce

\begin{tabular}{|c|c|c|}
\hline $\begin{array}{l}\text { AUTOR/ } \\
\text { ANO }\end{array}$ & TITULO & $\begin{array}{l}\text { PRINCIPAIS } \\
\text { ATUAÇÕES }\end{array}$ \\
\hline $\begin{array}{l}\text { ALMEIDA } \\
\text { JOÃO, I999 }\end{array}$ & $\begin{array}{l}\text { Amamentação: um híbrido natureza- } \\
\text { cultura }\end{array}$ & $\begin{array}{l}\text { Abordagem } \\
\text { amamentação como um } \\
\text { ciclo natural da vida da } \\
\text { mulher e das crianças. } \\
\text { Informa sobre a trajetória } \\
\text { da prática durante os } \\
\text { séculos e como a prática } \\
\text { passou a ser vista com } \\
\text { olhos mais severos e para } \\
\text { outros fins. }\end{array}$ \\
\hline $\begin{array}{l}\text { ARANTES } \\
\text { Cássia, 1995 }\end{array}$ & $\begin{array}{l}\text { Amamentação - visão das mulheres que } \\
\text { amamentam }\end{array}$ & $\begin{array}{l}\text { Explica a abordagem que } \\
\text { os profissionais de saúde } \\
\text { precisam ter em relação a } \\
\text { amamentação, } \\
\text { informando sobre a } \\
\text { conduta ética a ser } \\
\text { tomada, sem comentários } \\
\text { que excluam a mãe desse } \\
\text { momento. }\end{array}$ \\
\hline $\begin{array}{l}\text { SAMPAIO } \\
\text { Eliza, } 2020\end{array}$ & $\begin{array}{l}\text { Desmame precoce: todos nós somos } \\
\text { responsáveis por essa epidemia }\end{array}$ & $\begin{array}{l}\text { Define o desmame } \\
\text { precoce como um } \\
\text { abandono parcial ou total, } \\
\text { antes do sexto mês, sendo } \\
\text { um demonstrativo de } \\
\text { interesse de amamentar } \\
\text { na gestação. }\end{array}$ \\
\hline $\begin{array}{l}\text { RAMOS } \\
\text { Sebastiana, } 2016\end{array}$ & $\begin{array}{l}\text { Causas do desmame precoce e estratégias } \\
\text { de intervenção para sua prevenção. }\end{array}$ & $\begin{array}{l}\text { Resultados apontados } \\
\text { sobre o desmame precoce } \\
\text { e a falta de informação. } \\
\text { Transmissão de doenças } \\
\text { para o filho em idade } \\
\text { precoce e outros } \\
\text { problemas. }\end{array}$ \\
\hline
\end{tabular}

Fonte: Elaborado pela autora, 2021. 
O desmame varia de mãe para filho ou filho para a mãe e sabemos que existe a possibilidade de que ambas as partes podem rejeitar o ato.

Ainda nos dias atuais, mesmo com todos os informes sobre a amamentação ser algo natural e além de tudo, necessário, muitas pessoas tem a visão de que a mulher que amamenta seu filho em público, se não cobrir seus seios, está cometendo uma atitude vulgar ou algum ato de infração. De acordo com Arantes Cássia (1995), socialmente amamentar é um ato de amor, e a mãe que assume o lado negativo da experiência é considerada "desnaturada" e culpada de não amar o seu filho.

\begin{abstract}
As questões relativas à prática da amamentação natural têm-se configurado objeto de interesse para diferentes atores e grupos sociais ao longo da história. Em todas as épocas, o ser humano foi levado a construir rotas alternativas para responder à demanda das mulheres que, por opção ou imposição, trilharam o caminho do desmame precoce. Desde a secular figura da ama-de-leite até a emblemática vanguarda científica construída pelo marketing dos fabricantes de leites modificados, a alimentação do lactente tem servido a propósitos que não se circunscrevem exclusivamente às questões ligadas à saúde, denotando, em muitas situações, interesses relacionados à modulação de comportamento social e à oportunidade de auferir lucros de toda espécie. (ALMEIDA JOÃO, 1999).
\end{abstract}

Frente a isto, mães acabam rejeitando a prática de amamentar, e o que poderia ser um período de amor e uma condição especial para mãe e o filho, acaba tornando-se um pesadelo.

Existem pontos negativos e positivos com os dilemas que enfrentamos na alimentação de uma criança. Inerme de qualquer situação, a criança tem a necessidade de ser alimentada pela mãe.

Os pontos que causam desânimo na mãe, são por conta do seu resguardo e toda recuperação pós cirúrgica, passando por inúmeras mudanças e a adrenalina de ter um filho nos braços, porém, variam de cada organismo.

A sensação de desapontamento também chega na própria recuperação, sendo um momento de muitas mudanças, como: elevação ou perca do peso, perda de cabelo, pouco tempo para descanso, seios doloridos e a sensação de perca da beleza.

Isso tudo acarreta a rejeição em amamentar, além de uma sociedade que ocupa uma desvalorização da amamentação em lugares como shoppings, praças ou até mesmo em restaurantes. 
Mesmo com todas as vertentes negativas, temos muitos pontos positivos, que por vezes, são pouco citados, como a causa emocional e nutricional, tendo a principal importância para o organismo da criança. Assegurando a saúde e o bem estar de mãe e filho.

Muitas mulheres acabam optando o desmame pela queda do seio ou aparência diferente após a gravidez. E sabemos o quanto a estética afeta o psicológico de todas as mulheres.

Entre a taxa de desmame precoce, a maior influência é a falta de conhecimento, tanto durante a gestação quanto no pós parto. Acabam rompendo o aleitamento materno por medo e insegurança, até mesmo pela falta de confiança no processo, se sentindo despreparadas para lidar com essa nova fase. $\mathrm{O}$ maior caso de desmame são mães de primeira viagem, inclusive mães muito novas que não possuem conhecimento ou não foram aconselhadas durante o período em que souberam da gravides. Em muitos casos, existe o fato de ter vergonha de amamentar em público e saber como se comportar durante a amamentação.

Entre os aspectos que influenciam, temos o contentamento com a gestação, ou uma gravidez planejada. Diante disso, existem a diferenças de uma gravidez planejada e uma inesperada. A mãe pode se sentir sem vontade de seguir com todo o plano de amamentação ou seguir junto as fases do crescimento do filho. Os medos e inseguranças podem afetar no seu empoderamento, deixando sem motivações ao cuidar, assim dedicando dúvidas às suas escolhas de seguir ou não com a amamentação.

Alguns desses fatores mudam os aspectos mentais de uma mãe, como a depressão pós parto, assim na primeira semana do puerpério, acaba deixando o desânimo tomar conta. Após o início da primeira semana de amamentação é comum sentir um desânimo de seguir com o aleitamento, por fatores biológicos como a dor, desconforto e cansaço. Observa se que nas primeiras semanas é relatado muita dor e desconforto durante o ato da amamentação. São fatores que estão totalmente relacionados ao desmame, sendo eles iniciados alguns dias após o parto. Algum desses fatores da dor e do desconforto, é o sangramento, fissura, excesso ou perca de peso e também a flacidez que acabam deixando a mãe muito abatida e desmotivada após o nascimento da criança.

Nós, profissionais incentivadores do aleitamento, reproduzimos essa contradição social, quando desconsideramos o lado negativo da amamentação e utilizamos alienadamente seus aspectos positivos. Essa prática não tem colaborado para o 
aumento do tempo de duração do aleitamento, mas sim contribuído para que a mulher venha a camuflar suas reais necessidades através do "leite fraco, pouco leite...", pois o seu sentir o aleitamento contrapõe-se aos pressupostos por nós divulgados; ou ainda, experimentar sensações de frustação e culpa por não ter conseguido o ideal de amamentar tão apregoado. (ARANTES Cássia, 1995).

Percebemos que o afastamento físico entre a mãe e o filho é um fator agravante para a continuidade da amamentação. Mesmo o trabalho sendo a renda principal, a mãe se coloca na posição de não poder abandonar os afazeres para não prejudicar a rentabilidade e o sustento de sua família, aonde não consegue se dedicar a amamentação. Assegurando que existem leis que ajudam no processo, como o direito de dois períodos de 30 minutos cada, para amamentação do bebê até seus 6 primeiros meses de vida, a qualidade de vida e a socioemocional da mãe e do filho, melhoraria em níveis inestimáveis, porém o maior obstáculo não é a falta de leis que assegurem esse processo, mas sim a falta de implementação dos métodos viáveis nas empresas para que o aleitamento aconteça de forma contínua.

\section{CONCLUSÃO}

A partir do trabalho apresentado, podemos concluir que o aleitamento se faz necessário para o desenvolvimento imunológico do recém-nascido nos primeiros anos de vida. Não podemos descartar a vida e a experiência da mãe psicológica-emocional da mãe nessa fase da vida. Por mais que muitas mulheres relatem se sentirem confortáveis e terem momentos mágicos através da prática do aleitamento, precisamos olhar para as mulheres que estão no nível de desigualdade, que não são acolhidas e não tem assistência para viver esse momento da melhor forma possível.

A amamentação não precisa necessariamente ser um momento crucial para o relacionamento entre mãe e filho, mas a experiência não pode ficar marcada como traumática, pois pudemos estudar que existem casos que são levados como traumas para o resto da vida.

A mídia faz o seu papel de mascarar a realidade que milhares de mulheres vivem sobre a amamentação dolorosa, e com isso também mascaram os índices que comprovam que o desmame precoce é prejudicial a vida da criança. 
Precisamos de meios que incentivem o aleitamento, mas também o acolhimento socioemocional do indivíduo responsável por essa prática, para que assim, possamos diminuir os impactos negativos causados pelo desmame precoce.

\section{REFERÊNCIAS}

ALBUQUERQUE, C.M. et al. Fatores que interferem no Aleitamento Materno. Rev. Rene. Fortaleza, v. Io, n. 3, p. 6I-67, jul./set.2009. Disponível em: http://www.revistarene.ufc.br/ı0.3/html/6.htm>. Acesso em: o7 set. 2021.

ALMEIDA, JAG. Amamentação: um híbrido natureza-cultura [online]. Rio de Janeiro: Editora FIOCRUZ, 1999. I20 p. Acesso em: I5 ago. 2021. Pg 15.

ALMEIDA, Suzana Stefanini Campos de. Aleitamento Materno e Trabalho: entre as funções maternas e a responsabilidade profissional. Tese de Doutorado. Universidade de São Paulo.

AMARAL, Sheila Afonso do; BIELEMANN, Renata Moraes; DEL-PONTE, Bianca; VALLE, Neiva Cristina Jorge; COSTA, Caroline dos Santos; OLIVEIRA, Martiele da Silva; SANTOS, Iná S. Epidemiol. serv. saúde ; 29(I): ezor19219, 2020. Artigo em

Português | LILACS | ID: biblio-I090257. Biblioteca responsável: BR275.I. Localização: BR275.I.

ARANTES, Cássia. Amamentação - visão das mulheres que amamentam. Jornal de Pediatria - Vol. 71, No-4, 1995. Pg 198.

BARBOSA, M. B. et al. Fatores de risco associdos ao desmame precoce e ao período de desmame em lactantes matriculados em creche. Rev. Paul. Pedriatr., v. 27, n. 3, p. 272-28I, 2009 .

Bueno LGS e Teruya KM. Aconselhamento em amamentação e sua prática. Jornal de Pediatria - Vol. 8o, № 5 (Supl), 2004.

CABRAL, V. L. M; CAMPESTRINI, S. Programa de aleitamento materno - PALMA. Pontíficia Universidade Católica do Paraná. Mães desejosas de amamentar enfrentam despreparo profissional. Disponível em: http://www.pucpr.br/servicos/programas_saude/palma/maes.html. Acesso em: i mai. 2021. 
CALDEIRA AP, Goulart EMA. A situação do aleitamento materno em Montes Claros, Minas Gerais: estudo de uma amostra representativa. J Pediatria 2000; pg 76(I): 65-72.

CÉSAR, Elimartine Chagas; DOS SANTOS BARROS, Emanuela; DO NASCIMENTO ALVES, Jânio. Conhecimento de Estudantes do Ensino Médio Sobre Amamentação. TEMA-Revista Eletrônica de Ciências (ISSN 2175-9553), v. 14, n. 20; 21, 2014.

GIUGLIANI, Elsa R.J. Amamentação: como e por que promover. Artigo de revisão - Jornal Pediatra - Copryright 1944 by Sociedade Brasileira de Pediatria. 0021-7557/94/70-03/138. Vol. 70, № 3, 1994, pg 139.

LÚCIA MAGALHÃES BOSI, M.; TAVARES MACHADO, M. Amamentação: Um resgate histórico. Cadernos ESP - Revista Científica da Escola de Saúde Pública do Ceará, [S. l.], $\quad$ v. $\quad$ I, $\quad$ n. $\quad$ I, p. I4-22, 2019. Disponível em: //cadernos.esp.ce.gov.br/index.php/cadernos/article/view/5. Acesso em: 20 out. 202I.

MARTINS, Maria Zilda Oliveira e SANTANA, Lícia Santos. BENEFÍCIOS DA AMAMENTAÇÃOPARA SAÚDE MATERNA. Interfaces Científicas -Saúde e Ambiente $\cdot$ Aracaju $\bullet$ V.I $\bullet$ N.3 $・$ p. 87-97 $\bullet$ jun. 2013.

MATERNO, Aleitamento; COMPLEMENTAR, Alimentação. Saúde da criança: nutrição infantil. 2009.

MOUTINHO, Karina. Desmame precoce sob o olhar da psicologia. Revista PEDIATRIA MODERNA. Edição: Ago or V 37 N 8. 2010.

PATIL, Divya Sussana et al. A mixed-methods systematic review on barriers to exclusive breastfeeding. Nutrition and Health, v. 26, n. 4, p. 323-346, 2020.

RAMOS, Sebastiana Batista. Causas do desmame precoce e estratégias de intervenção para sua prevenção. Universidade Federal de Minas Gerais. Faculdade de Medicina. Núcleo de Educação em Saúde Coletiva. Governador Valadares, 20II. 29f.Monografia (Especialização em Atenção Básica em Saúde da Família).

SAMPAIO, Eliza. Desmame precoce: todos nós somos responsaveis por essa epidemia. Blog Leiturinha, 202I. Disponível em: < https://leiturinha.com.br/blog/desmameprecoce/>. Acesso em: io nov. 202I. 
VIEIRA, Doralice Barbosa. Desvantagens do desmame precoce e o papel do enfermeiro. Brazilian Journal of Development, v. 6, n. 6, p. 35163-35184, 2020.

WHO - World Health Organization. The optimal duration of exclusive breastfeeding. Note for the press n. 7. Geneva: WHO; 20oI. 